\title{
PROPAGANDA POLITICA NO PRINCIPADO ROMANO: A FAMILIA COMO UM ELEMENTO DA CONSTITUIÇÃO
}

\author{
Maren Guimarães Taborda ${ }^{1}$ \\ Alfredo de J. Flores ${ }^{2}$
}

\begin{abstract}
"Nenhuma razão séria parece ter levado a manter sob tutela as mulheres púberes. Porquanto a razão que geralmente se alega, a saber que elas são frequentemente enganadas por sua levitas animi, e que seria equitativo deixar que fossem governadas pela autoridade de seus tutores, parece mais ilusória do que verdadeira: as mulheres púberes, com efeito, tratam pessoalmente dos seus assuntos, e em certos casos o tutor só interpõe a sua autoridade por formalidade; muitas vezes, ele é mesmo obrigado pelo magistrado a constituir-se como garantia contra sua vontade." (GAIO, 1, 190).
\end{abstract}

\section{Resumo}

Trata o presente ensaio de analisar o momento de transformação da constituição romana, na qual a civitas interferiu na família, servindo a reforma dos costumes de elemento de propaganda. A primeira hipótese explicitada é a de que, em Roma, até a época da instauração da monarquia militar, o direito público não dizia respeito às relações familiares. Com a constituição do principado, surgiu um conjunto normativo que, interferindo diretamente na organização da família e na liberdade de escolha individual, acabou trazendo para o campo da política a solução dos conflitos intrafamiliares, com a criação de procedimentos judiciais públicos, não submetidos à lógica do processo formulário (semiprivado), principalmente para disciplinar as relações sexuais (os juízos públicos de adultérios) e, por conseguinte, equacionar a questão da natalidade. O método utilizado na investigação é o histórico-jurídico, porque a historicidade do direito é constitutiva e parte integrante dos acontecimentos. Ao estilo do realismo histórico, o estudo procura compreender e explicar os fundamentos da prática política e a propaganda, os quais foram as bases do novo regime, com o auxílio dos resultados científicos da investigação histórico-jurídica sobre o tema (revisão bibliográfica) e das fontes documentais primárias (textos de juristas, políticos e historiadores da Antiguidade Clássica).

Palavras-chave: Constituição; Ordenação Social; Família; Propaganda Política; Leges Iulize

\footnotetext{
${ }^{1}$ Mestre em Sociedade e Estado em Perspectiva de Integração pela Universidade Federal do Rio Grande do Sul e Doutor em Sociedade e Estado em Perspectiva de Integração pela Universidade Federal do Rio Grande do Sul. Professor Titular da Faculdade de Direito da Fundação Escola Superior do Ministério Público do Rio Grande do Sul. E-mail: tabordamaren@yahoo.com.br

${ }^{2}$ Professor Associado da Faculdade de Direito da Universidade Federal do Rio Grande do Sul - UFRGS. Professor Permanente do Programa de Pós-Graduação em Direito - UFRGS. Doutor em Direito e Filosofia pela Universitat de València - Espanha. E-mail: ajdmf@yahoo.com.br
} 


\section{INTRODUÇÃO}

$\mathrm{Na}$ tradição política do Ocidente, o conceito de democracia envolve, no mínimo, três elementos: isonomia (os membros da coletividade se reconhecem abstratamente como iguais); publicidade (todas as decisões importantes para a vida social devem ser tomadas às claras, à luz do dia); e proeminência da palavra (a democracia é o regime político do consenso, que pressupõe o dissenso), pois a arma principal da política deixa de ser a força, só utilizada em última instância (ERNOUT; MEILLET, 1985, p. 502; ARISTÓTELES, 1998, p. 49).

A política, por sua vez, fundada na convivência pública entre diferentes - na pluralidade de homens distingue-se de todas as demais formas de convívio humano pela liberdade. O próprio viver é "estar entre homens", e subjaz a esta tradição uma idéia de poder baseada no consentimento e não só na violência. O poder, ação concertada que funda uma comunidade, só pode existir em um espaço que é público, por meio de um "encontro" público que faz surgir o consentimento. Daí que o poder (a esfera pública) é, simultaneamente, o espaço das "aparências" e o lugar da "isonomia”, isto é, um espaço em que a interação entre indivíduos iguais se dá por meio da livre troca de opiniões plurais e da ação (ARENDT, 2001, p. 36).

A ação, condição humana da pluralidade, não está enraizada na mortalidade e sim na natalidade, pois essa "se compromete em estabelecer e preservar os corpos políticos, cria a condição para a recordação, isto é, para a história" (ARENDT, 1993, p. 23). A organização política (pública) está em direta oposição à associação natural cujo centro é o lar (oikia/domus) e a família. Há, pois, uma taxativa distinção entre o que é seu e o que é comum, entre o "campo familiar e o campo político". Daí que "público" se opõe a "privado", e privatus significa o que é particular, individual (a origem latina de privatus: prius \{prei-u-os\} e, hipoteticamente, quer dizer o que está adiante e, depois, o que está isolado dos outros) (ERNOUT; MEILLET, 1985, p. 502).

$\mathrm{Na}$ esfera do privado, o que unia os homens eram os penates, deuses domésticos, e a força e a violência se justificavam porque eram os únicos meios para dominar a necessidade. O "público" é a liberdade e só o extraordinário sentido político dos romanos manteve as esferas separadas, mas coexistentes. Assim, à esfera pública pertence a ação, a liberdade, a lex publica, a ordenação da sociedade; à esfera privada, corresponde o labor (o disse Arendt), a necessidade, a lex privata, a ordenação da família e dos negócios interfamiliares.

O conceito de auctoritas bem demonstra essa dualidade, uma vez que tal princípio exerceu função decisiva na regulação da família e da civitas. Com efeito, a vida familiar romana se baseava em relações autoritárias de supremacia do pater. A soberania doméstica implicava domínio absoluto sobre pessoas e bens: ao lado dos 
escravos e dos estrangeiros, que no campo do direito privado estavam submetidos ao domínio ou podiam cair nele, encontravam-se todas as pessoas submetidas a potestas, que no direito privado estão em propriedade alheia, mas do ponto de vista da civitas se denominam liberi, em contraposição aos escravos. Assim, fora da relação mesma de supremacia, não podiam existir relações de direito privado entre o titular do poder e seus submetidos. Como a vida do Estado também estava organizada segundo o princípio da autoridade, todo o direito das magistraturas estava construído com a finalidade de valorá-la e conservá-la. Nas mãos dos titulares do imperium (supremacia do Estado que se personifica no magistrado), como também dos censores, ediles e tribunos, residia a pública disciplina, como nas mãos do paterfamilias a disciplina doméstica. O poder (potestas) dos magistrados significava a competência para expressar, com sua vontade, a vontade da civitas, gerando para esta direitos e obrigações. Eis porque potestas, no Direito Romano, tem dois significados: o primeiro, quando exercida no âmbito familiar ou das relações entre famílias; o segundo, quando exercida por quem detinha imperium. (SCHULZ, 1990, p. 187-209; MOMMSEN, 1942, p. 11-19; ARANGIO-RUIZ, 1994, p. 38-39).

Em Roma, com a ascensão de Otávio, instituiu-se uma nova ordem constitucional, baseada em quatro instituições: um rei salvador deificado; um Estado mundial no qual as cidades-estados locais constituíam as células do corpo político; um exército profissional; e um serviço público civil profissional. O expediente político utilizado tinha dupla face: para os povos a leste, mostrava-se Otávio como um rei-salvador deificado; para o povo romano, usava uma máscara, exercendo sua autoridade absoluta e inquestionável, como se dispusesse virtualmente dos poderes constitucionais reunidos das principais magistraturas da República Romana. A reforma dos costumes da família -, de outra parte, fez parte de seu projeto político como um elemento de propaganda.

Propaganda é a publicidade que deixa de ter a virtualidade de racionalizar a dominação política e passa a servir à manipulação do povo na mesma medida em que se constitui em legitimação ante ele: o "povo" continua sendo citado para fins de aclamação, mas está tão distante do exercício e da distribuição do poder que a racionalização dele mal pode ainda ser estimulada através do princípio da publicidade, do tornar público. Político genial (talvez o maior de Roma), Augusto compreendeu que a natalidade é o centro da vida política e que era preciso adotar uma política de estímulo de aumento da população livre, bem como de garantia de posições para as classes altas. Isso explica o conteúdo das Leges Iulize sobre a família, que acompanharam a reforma do Estado. Ao utilizar a moralização dos costumes com intenção claramente propagandística, Augusto acabou por ganhar adesão social para o seu projeto de instauração de uma nova ordem constitucional, que perdurou por mais de 200 anos (BURDESE, 1987, p. 153).

Sendo assim, é objetivo deste ensaio analisar o momento de transformação da constituição romana, na qual a civitas interferiu na família, servindo a reforma dos costumes de elemento de propaganda. A primeira 
hipótese que se pretende explicitar é a de que, em Roma, até a época da instauração da monarquia militar por César e Augusto, o direito público não dizia respeito às relações familiares, pois esta era concebida como idêntica à civitas, cabendo ao seu chefe - o paterfamilias - a disciplina doméstica. Com a constituição do principado, surgiu um conjunto normativo que, interferindo diretamente na organização da família e na liberdade de escolha individual, acabou trazendo para o campo da política a solução dos conflitos intrafamiliares, com a criação de procedimentos judiciais públicos, não submetidos à lógica do processo formulário (semiprivado), principalmente para disciplinar as relações sexuais (os juízos públicos de adultérios) e, por conseguinte, equacionar a questão da natalidade.

O método utilizado na investigação é o histórico-jurídico, porque a historicidade do Direito é constitutiva e parte integrante dos acontecimentos. Relato perspectivista, individuante e seletivo, procura entender os acontecimentos segundo o seu tempo e lugar, individualiza o evento por dois parâmetros fundamentais (geográfico e cronológico) e julga importante relatar os resultados visíveis de uma determinada concepção de Estado e de Sociedade que acabou por se impor. Ao visar à explicação condicional e à determinação de possibilidades retrospectivas, o ensaio utiliza a explicação e a compreensão para relatar "o que foi" e o faz por argumento formal (contextualismo), ao estilo do realismo histórico, na medida em que procura compreender e explicar os fundamentos da prática política e a propaganda, os quais foram as bases do novo regime instituído por Augusto (ABBAGNANO, 1970, p. 485-487; WHITE, 1992, p. 16-22).

A exposição está organizada dedutivamente, partindo do geral - a explicitação do significado da dicotomia público/privado no final da República e da nova estrutura constitucional - (1) e (2), para o particular, ou seja, a reflexão sobre a legislação de Augusto dos anos 17/18 a.C. - leges Iuliz - e sua importância no novo regime (3), com o auxílio dos resultados científicos da investigação histórico-jurídica sobre o tema (revisão bibliográfica) e das fontes documentais primárias (textos de juristas, políticos e historiadores da Antiguidade Clássica).

\section{PÚBLICO E PRIVADO NA ROMA REPUBLICANA}

A dicotomia público/privado é categoria central das disciplinas sociais e em geral históricas, entre as quais o Direito, que através do uso constante e contínuo, tem como função delimitar, representar e ordenar o campo de investigação. A relação público/privado é pressuposto essencial da esfera política, e não da esfera econômica ou jurídica, porque tais noções são limitativas entre o que é político e não político e são capazes de determinar especificamente domínio do político. Assim Paul Veyne se expressa:

No privado encontra-se o que possuímos de mais precioso, que pertence somente a nós 
mesmos, que não diz respeito a mais ninguém, que não deve ser divulgado, exposto, pois é muito diferente das aparências que a norma exige guardar em público. (VEYNE, 1996, p. 10).

Se qualquer sociedade é forçosamente política, a vida humana resta cindida, de um lado, em uma vida pública, que faz com que o homem seja parte, inevitavelmente, de uma unidade política e, de outro, em uma vida privada, que faz com que ele conserve com seus semelhantes os laços de reciprocidade e de associação (FREUND, 1965, p. 15). Em tal perspectiva, tudo o que se refere à família, nas sociedades contemporâneas, pertence ao espaço do "privado". Em Roma, contudo, não era assim, pois só tinha ius aquele que fosse, simultaneamente, livre, cidadão romano e organizado em uma família, não submetido a qualquer outro poder de natureza privada (sui iuris).

A Antiguidade Greco-Romana, todavia, não conheceu a distinção do ius até, pelo menos, o Baixo Império Romano, e esta foi ganhando consistência com o progresso da noção de Estado, ainda que gregos e romanos tivessem a noção de justiça distributiva e justiça corretiva. A gênese da sociedade arcaica nos oferece a explicação: a família, em que se centra o Direito Privado, é um organismo político, idêntica à civitas ou a polis. $\mathrm{O}$ paterfamilias é, ao mesmo tempo, rei, sacerdote e proprietário. A lei, entre romanos, gregos e hindus, era, primordialmente, parte da religião, isto é, os códigos antigos eram conjunto de ritos e prescrições litúrgicas, além de regras de conduta social. As regras relativas ao direito de propriedade e ao direito das sucessões, por exemplo, encontravam-se junto às relativas aos sacrifícios, à sepultura e ao culto dos antepassados. Paolo Coliva assevera:

[...] o único modo conhecido de definição da respublica romanorum está na fórmula dominante Senatus populusque romanus, que exprimia, nessa aproximação não disjuntiva, os dois componentes fundamentais e permanentes da civitas romana: o Senado, núcleo das famílias gentílicas, originárias, representada pelos patres e o Povo, ou grupo dêmico, progressivamente integrado e urbanizado que passou a fazer parte do Estado com a queda da monarquia. (COLLIVA, 1996, p. 986).

Por isso, havia em Roma uma religião pública e outra doméstica; um Direito Penal público e um Direito Penal privado, e a distinção está sempre baseada nas diversas esferas às quais se refere o delito e a necessidade de sua repressão. O delito é público quando ofende ao Estado e privado quando a ofensa é inferida à gens, inclusive a um de seus membros. A principal característica do Estado Romano primitivo é o persistente caráter voluntário e privado da administração da justiça - a iurisdictio. Transcorrem mil anos ou mais até que o processo passasse às mãos da autoridade pública ou do magistrado; e mais, a crise que transformou o processo em inteiramente público, iniciando a jurisdição do Estado, coincide precisamente com a crise da romanidade (BONFANTE, s.d., p. 143-149). Daí que a distinção "público/privado" se aplicava à ager(terra) e à lexe não ao ius.

O termo publicum foi associado ao ius para designar regra obrigatória para todo o populus. Em Cícero, aparece o primeiro traço desta divisão, mas ele não a pensa com o significado ao que hoje conhecemos: a distinção visava separar o direito que põe em vigor a vontade do Estado daquele que decorre da vontade dos particulares. 
Ela não implicava uma verdadeira divisão do ius, relativamente ao seu objeto e finalidade, mas somente referente a sua fonte imediata. Sob a denominação ius publicum estavam também compreendidos interesses políticoreligiosos. A distinção, como a conhecemos, teria sido influência de ideias estrangeiras à tradição romana, decorrentes do período de expansão mundial, pois o ius civile se viu surpreendido por uma súbita transformação econômica e social, que ruiu suas bases e impôs a adoção de direitos estrangeiros.

Em resumo, no período de expansão econômica, em que a comunidade inicialmente formada por patrícios e plebeus se transformou no centro e capital do Império, é que se desvanece o paralelismo entre o Direito Público e o Direito Privado e que a organização do Direito Público encontra sua definitiva fisionomia. O ius publicum se referia a todas as regras jurídicas em que estava implicado o populus e cresceu, rapidamente, às expensas do Direito Privado (substituição dos delitos privados pelos delitos públicos, generalização da justiça promovida por funcionários). Direito Público e Direito Privado passaram a ser a divisão suprema do ius, salvaguardando os interesses dos particulares ou defendendo os do Estado, cristalizada na definição que aparece no Corpus Iuris (GARCÍA DEL CORRAL, 1989, p. 197). ${ }^{3}$ Registre-se que o direito público não cessou de pretender dominar a esfera do direito sacro.

\section{A NOVA ORDEM CONSTITUCIONAL}

Antes de Augusto, Cesar já tinha posto as bases da nova ordem constitucional, cujas finalidades eram levantar a ordem política, militar, intelectual e moral de sua nação da decadência a que haviam chegado. Fundador de uma monarquia militar, uma "democracia à romana", sua divisa e pensamento eram "melhorar a sorte dos devedores, colonização transmarítima, nivelamento insensível das classes no Estado e poder executivo independente da supremacia do Senado" (MOMMSEN, 1983, p. 1863). A monarquia absoluta, assim, havia chegado a ser a solução indispensável e lógica quando ele foi declarado "imperador perpétuo".

Otávio, ao ser aclamado Augusto, inicia o processo de consolidação da monarquia militar, ganhando, progressivamente, novos poderes. $\mathrm{O}$ poder do imperador não excedia, em princípio, ao poder consular e proconsular, tribunício e pontifício. Aos poucos, vão se concentrando os poderes supremos, militar, judicial e administrativo na pessoa do príncipe, de modo que ele ganha a supremacia religiosa na cidade, o direito a decretar, tendo seus decretos força de lei, e o Senado fica rebaixado a mero corpo consultivo, sendo ressuscitados o patriciado e a prefeitura urbana. O monarca pode nomear, por adrogação, ${ }^{4}$ um sucessor (TÁCITO, s/d, p. 14-

\footnotetext{
${ }^{3}$ D. 1.1.1.2, UlPIANO. Doravante, todas as citações do Corpus Iuris (Digesto, Institutas, Codex e Novelas) são da obra de GARCÍA DEL CORRAL (1989).

${ }^{4}$ Adrogação era a adoção de pessoa sui iuris, feita na assembléia, e criava um vínculo agnatício. Em contraposição à cognação (parentesco cosanguíneo, que significa "nascer de", idéia de geração natural), agnação, que é civil (não natural), é o que deriva de
} 
$15)$.

Segundo Suetonio, Augusto deixou "uma cidade de mármore onde se encontrava uma cidade de tijolo", reestabeleceu cerimônias religiosas antigas, como o augúrio de salvação, lupercais, flaminato de Júpiter, os jogos seculares e os jogos em honra aos deuses lares (SUETONIO, s/d, p. 62-66); restringiu as reuniões do Senado a duas por mês, proibindo a publicação de seus atos; criou novos cargos no Estado (curatela dos monumentos públicos, estradas, águas, distribuição de grãos) e muitas recompensas ao mérito militar; elevou o censo dos senadores para 1.200 sestércios, fez muitos donativos ao povo e construiu aquedutos, ultrapassando a todos os seus predecessores no que toca à freqüência, variedade e magnitude dos espetáculos públicos (SUETONIO, s/d, p. 71). Nos anfiteatros, separou os soldados do povo, proibiu o uso do preto nas vestimentas, estabeleceu lugares à parte para as Vestais e não permitiu que as mulheres vissem gladiadores.

A consolidação do poder imperial se fez por intermédio de leis, senatus-consulta e plebiscitos, de modo a conferir legitimidade ao novo regime. Daí a Lex de nomine Augusto Cæesari tribuendo, de 28 a.C., na qual se lhe atribuiu o nome de Augusto; ${ }^{5}$ a Lex Pacucia da mense Sextil, de 27 a.C., que deu o nome de Agosto para o sexto mês; a Lex Octaviani dictadura, de 18 a.C., que Otávio recusou; ${ }^{6}$ a Lex Iulia de suffragis in iudiciis, de 22 a.C.; a Lex Iulia de collegis, de 21 a.C., através da qual o príncipe dissolveu os colégios existentes e subordinou a formação de novos à aprovação preventiva do Senado (ROTONDI, 1990, p. 448-449; AUGUSTO, Res Gestae. \$5).

No âmbito político, importante foi a Lex Iulia de ambitus, de 18 a.C., plebiscito proposto por Augusto sobre o delito de corrupção eleitoral. Estabeleceu a pena de aqcuae et ignis interdictio (perda da cidadania/ deportação pela violência) para quando se exercesse a violência; em casos de simples corrupção, multas e inabilitação para o exercício de cargos públicos por cinco anos. Já pelas Leges Iulize iudiciorum publicorum et privatorum, de 17 a.C., ficou estabelecida a duração do processo em, no máximo, dezoito meses, entre outras disposições. No plano privado, estabeleceu leis santuárias (Lex Iulia Sumptuaria, de 18 a.C.), limitando os gastos com banquetes; fez leis limitando o luxo das mulheres (Lex Iulia de vestitu et habitu) e o luxo das construções (Lex Iulia de modo ædificiorum urbis), como também leis sobre adultérios; proibiu casamentos entre as

uma "agregação", porque agnação significa "nascer junto a". Era o princípio dominante na regulação da família, da herança, das tutelas e da manus (poder marital advindo de uma convenção feita com a esposa). Augusto adrogou Tibério, filho de Lívia; seus sucessores mantiveram, no geral, tal prática, associando ao poder o sucessor e adotando-o para os fins jurídicos. Exceção bastante conhecida é o caso de Cômodo, filho de Marco Aurélio pelos dois parentescos (ERNOUT-MEILLET, 1985, p. 430). Verbete: nãscor:

${ }^{5}$ Existe dúvidas se tal lei foi um SC ou uma lex rogata proposta por L. Munatius Plancus. (ROTONDI, 1990. p. 448-449).

${ }^{6}$ Expressamente: "Durante o consulado de Marco Marcelo e Lucio Arruncio não aceitei a magistratura de Ditador, que o Senado e o povo me conferiram para exercer tanto em minha ausência quanto durante minha presença [em Roma]. Não quis declinar a responsabilidade das provisões alimentares, em meio a uma grande carestía; e de tal modo assumi sua gestão que, poucos dias mais tarde, toda a Cidade se achava livre de qualquer temor e perigo, à minha só custódia e sob a minha responsabilidade. Não aceitei o 
diferentes ordens, restringiu a duração dos esposais, impôs limites ao divórcio e restringiu as manumissões, impondo àqueles postos a ferros ou submetidos à tortura o estatuto infamante dedicticios (TÁCITO, s/d, p. 14; MODESTINO, D.48,14; MACER, D.48.15.3; PAULO, V, XXX,1984, p. 208; GAIO, 4.30, apud DOMINGO, 2002, p. 203-204)?

É possível localizar a inspiração do novo regime nas teses de Políbio, referindo-se às constituições de Esparta e de Roma, como mistas, ou seja, uma "mistura, combinação, integração, fusão" das três formas clássicas de governo, monarquia, aristocracia e democracia. Quando alude à constituição de Esparta, assegura que foi pensada:

de tal maneira que nenhum de seus componentes pudesse crescer indevidamente e degenerar nos males inerentes, e que, sendo a força de cada um, contrabalançada pela dos outros, nenhum deles prevalecesse e se sobrepusesse aos outros, e assim constituição permanecesse por longo tempo em estado de equilíbrio, como uma nau singrando o mar contra o vento [...]. (POLÍBIO, 1996, p. 331).

De acordo com Políbio, o governo misto é ideal por ter estabilidade, imparcialidade (evita que uma classe ou grupo prevaleça sobre os demais) e porque impõe o controle de poder de uma classe ou grupo sobre outro (verdadeiro e autêntico precedente histórico do balance of powers).

O regime também se inspirou (aparentemente) nas teses de Cícero, ainda que o resultado fosse a abolição, em parte, das liberdades republicanas. Para Cícero, República é coisa do povo, da multidão (CÍCERO, 1980, p. 147). Nenhuma das três formas clássicas de governo satisfaz isoladamente: a melhor é uma quarta forma, que combina elementos das três - é a Constituição mista. No conselho (Senado), está a nobreza; a liberdade, no povo.

Cícero aceitou a necessidade de confiar a res publica a uma pessoa grande e poderosa, para acabar com a anarquia e educar os cidadãos na virtude, regulando-os pelos costumes e leis da república. Roma é, então, concebida como um povo organizado, não somente sob o fundamento da utilidade comum, senão que, antes de tudo, está sob a convivência jurídica, o que, com respeito à comunidade humana, ocupa uma posição central, capaz de organizar o mundo. O Estado, por sua vez, se conserva mediante a educação dos costumes, a observância dos mores maiorum, culto à honra e à virtude cívica. É submetida ao censor a atividade dos poetas dramáticos e, ao varão, cabe a correção "conveniente" da esposa. É precisamente essa a inspiração de Otávio quando assume os poderes de censor (CÍCERO, 1980, p. 147 et seq).

Com grande tino político, o Imperador sopesou a força com o liberalismo. Em sua propaganda, promoveu o Estado contra os abusos contraditórios da oligarquia e da democracia e combinou o poder militar com o material que restava das instituições republicanas. Ademais, conciliou em sua pessoa o poder aristocrático

consulado que então se me ofereceu, para esse ano e com caráter vitalício." Disponível em: <http://www.thelatinlibrary.com>. Acesso em: 27 fev. 2017.

${ }^{7}$ Doravante, as citações ao texto gaiano foram extraídas do texto de Domingo et al. (2002). 
dos cônsules e o poder democrático dos tribunos. Sem criar potestates novas, governou por sua autoridade; adotando a tese da Constituição mista e tripla, o princeps controlou as armas, a Justiça e a religião através da Cura Morum. Mantendo a ideologia da República, a nova constituição preserva a vocação jurídica e liberal de Roma, fundando o que mais tarde se chamaria "monarquia esclarecida”, como o explicita o próprio príncipe: “[...] Desde então fui superior a todos em autoridade, porém não tive mais poderes que qualquer outro dos que foram meus colegas nas magistraturas" (AUGUSTO, Res Gestae, \$34). Assim, pela primeira vez e de um modo contundente, o Estado (a civitas) interferiu na esfera familiar, para discipliná-la, atendendo a finalidades coletivas.

\section{A FAMÍLIA E AS LEGES IULIAE}

A determinação da posição da família no ordenamento jurídico, principalmente em relação à máxima organização jurídico-política que delimita e funda o ordenamento mesmo, sempre constituiu um problema delicado. Família é instituição e como tal, possui elementos de direito público e privado. Família é a comunidade mínima originária, base da organização social.

A verdadeira significação da família em Roma é a propriedade: designa o campo, a casa, o dinheiro os escravos. É a família uma pluralidade unificada por meio de seu chefe, de modo tal que revela, imediatamente, o nexo axiológico entre a ideia de autoridade e de legitimidade. $O$ poder do monarca se legitima em virtude da analogia entre a família e a comunidade citadina; referindo à autoridade política a autoridade paterna, se reduz o estado à família, o que a põe como paradigma. Para Sêneca, "a família é uma pequena república".

A família romana não é decorrência de vínculos de sangue; é, antes, uma estrutura jurídica (iure proprium familiam dicimus plures personas, quae sunt sub unius potestate aut iure subiectae). Assim, Ulpiano:

A denominação de "família" se refere também à significação de alguma corporação que está compreendida ou no direito próprio de seus indivíduos, ou no que é comum a toda cognação. Por direito próprio chamamos família a muitas pessoas que, ou por natureza, ou de direito, estão sujeitas ao poder de um só, por exemplo, o pai de família, a mãe de família, o filho de família, a filha de família, e os demais que seguem em lugar destes, como os netos e as netas e outros descendentes. Porém se chama "pai de família" o que tem o domínio da casa; e com razão é chamado com este nome, ainda que não tenha filho; porque não designamos só a pessoa dele, senão também seu direito. (D.50,16,195,2).

A família primitiva, a gens ou a tribo não possuem natureza distinta da do Estado, pois são aglomerações nascidas para a ordem e defesa e uniformes em sua composição (BONFANTE, s/d., p. 143-149). ${ }^{8}$ Realizam todas as atividades próprias do Estado e o vínculo que liga as pessoas aos grupos só aparentemente é consanguíneo. A gens não é outra coisa senão o núcleo político precedente a civitas, uma aglomeração de famílias

\footnotetext{
${ }^{8}$ Uma crítica à hipótese de Bonfante de a arcaica família romana ter-se constituído como um organismo político acha-se em VOCI, 1956.v.1.p. 101-146.
} 
que se reivindicam um ancestral comum e que, segundo as circunstâncias ou fortuna de uma determinada gens, pode constituir, com seus próprios sujeitos e escravos, uma grande casa, um burgo ou um município.

$\mathrm{Na}$ linguagem da Lei das XII Tábuas, familia é tanto as coisas quanto as pessoas, designando todo o complexo das coisas do Direito, que tinha o paterfamilias como chefe instituído, conferindo-lhe simultaneamente a titularidade sobre o patrimônio essencial e permanente do grupo, mesmo sobre as coisas extrapatrimoniais, como as coisas sagradas e os sepulcros (ULPIANO, D.50,16,195,1). Por conseguinte, a família constituía o objeto da hereditas (herança), de modo que nas fontes, os termos se intercambiam em fórmulas como familiam habeto (o que tem a família), familia pecuniaque (os bens da família) e nos institutos mancipatio familiae (testamento mancipatório), ${ }^{9}$ familia emptor (comprador da família - testamenteiro) e a actio familiae erciscundae (ação de qualquer um dos herdeiros para exigir a divisão da herança). ${ }^{10}$

No mundo romano imperial, precisamente após reformas de Augusto, a família servia ao interesse do Estado assim como do indivíduo; o Direito Familiar romano, no entanto, é parte do Direito Privado. Na família romana, até a República, as mulheres estavam submetidas à tutela agnatícia, cujo fundamento residia no fato de que as mulheres não participavam da esfera pública - o campo da política - e não tinham qualquer poder sobre outrem (a mulher é o início e o fim de sua própria família, disse Ulpiano). No que concerne a si próprias, no trato de seus negócios, não eram, contudo, consideradas congenitamente incapazes. No final da República, ruiu a base costumeira da tutela mulierum e ficou evidente que se tratava de uma instituição absolutamente irracional (SCHULZ, 1960, p. 174-175).

Esta ratificação puramente formal, segundo Yan Thomas, fazia-se necessária nos seguintes atos: para

\footnotetext{
${ }^{9}$ A mancipatio era negócio solene, formal, que, desde muito cedo na história jurídica romana teve múltiplos usos. Os juristas, com suas técnicas, auxiliando os privados nos seus negócios, transformaram a solenidade que, em tempos antigos, servia para transmitir certa classe de coisas submetidas ao poder do pater familias - res mancipi - em um negócio jurídico abstrato geral com múltiplos usos na esfera de potestas intrafamiliar e, em alguns casos, nas relações interfamiliares. Utilizada a mancipatio para extinguir a patria potestas (realizada três vezes se o filho submetido fosse homem e uma vez se fosse mulher, neto ou neta), denominava-se emancipatio; para estabelecer o regime do poder marital no casamento (manus), coemptio; com o fito de garantir obrigação (automancipação do devedor), nexum; finalmente, para conferir eficácia à declaração de última vontade em relação à família (também constituída pelos bens), denominava-se testamentum per aes et libram, porque da mancipatio também se dizia ser um "negócio pelo bronze e pela balança." Pela mancipatio feita para o último efeito, o testador alienava todos os seus bens presentes e futuros a uma outra pessoa (familiae emptor), que se convertia em proprietária de ditos bens, na morte do testador. Ao realizar a alienação, o testador dava instruções ao familiae emptor referentes à distribuição que este devia efetuar quando o testador morresse. Tais instruções faziam-se oralmente, na nuncupatio, ou constavam das tabula testamentia que se referia a nuncupatio. No período clássico, o testamento mancipatório foi o único testamento ordinário.

${ }^{10}$ A actio familiae erciscundae era a ação de qualquer um dos co-herdeiros para exigir a divisão da herança. Chamada usualmente pelos autores modernos como um juízo divisório, esta ação constituía um grupo especial no Edito do Pretor, ao lado da actio communi dividundo e da actio finium regundorum. Considerando que família significa também patrimônio, erciscundae ou herciscundae equivale a dividir. Neste procedimento, o juiz tinha amplo poder discricionário, o que não era comum. Mediante essa ação, por exemplo, poderia dividir-se um lote de terra por tantos quantos fossem os herdeiros, ou, ainda, adjudicar-se a terra a um só herdeiro, impondo-se a este a obrigação de indenizar os demais. Desta forma, o adjudicatário do lote se tornava dono ex iure
} 
contrair uma obrigação de acordo com as normas antigas do Direito Civil: quer dizer, por uma promessa solene e unilateral, que não era explicitamente garantida por qualquer contrapartida; em segundo lugar, para alienar um bem cuja transferência exigia o ato formalista da mancipação (bem de raiz, propriedades construídas e escravos) (THOMAS, 1993, p. 186). A formalidade da aprovação tutoral, porém, era supérflua para contrair casamento; para constituir um dote (salvo se fosse sob a forma estipuladora da promessa); para fazer testamento; para fazer contratos; para alienar bens cuja transferência não exigisse o rito da mancipação (ou seja, de fato, todas as mercadorias); para se reembolsar dívidas e para aceitar uma sucessão.

Antes das leis Júlias e da supressão da tutela agnatícia, em situações especiais, uma mulher podia, socorrendo-se da Lex Atilia de tutore dando, de 210 a.C., também exigir que o pretor urbano the nomeasse um tutor para garantir a seus atos jurídicos todas as condições formais de validade, prática esta que, durante o Império, estendeu-se à Itália e às províncias. Mera formalidade, considerava-se que os atos eram praticados exclusivamente pela mulher e esta, contrariamente às impúberes, não podiam intentar ações para se ressarcirem de danos sofridos por gestão imprudente ou desonesta da tutela. ${ }^{11}$ Taborda explicita:

no último século antes de nossa era, as mulheres romanas não se contentaram mais com a roca, o fuso e os cuidados da casa, começaram a tomar parte na vida pública, embora continuassem excluídas dos comitia, do Senado e das magistraturas. Exemplo significativo sobre a participação das mulheres no mundo dos negócios é o caso de Terência, mulher de Cícero, que administrou seus próprios bens com independência absoluta, valendo-se tãosomente da ajuda de seus libertos, pois não se encontrava in manu, e não há notícia de que estivesse sob tutela" (TABORDA, 2010, p. 86).

A novidade das Leges Iulix foi a instituição de uma ordem moral relativamente igualitária, na medida que retirava do paterfamilias muito de seus poderes originários. Pela Lex Iulia de maritandis ordinis, levada aos conselhos, se proibia aos senadores e seus filhos e filhas que celebrassem esponsais ou tomassem como esposa(o) libertos, ou filhos daqueles que haviam exercido as artes cênicas (SUETONIO, 1975, p. 34). ${ }^{12}$ A propósito de reforma dos costumes, foi proposta em virtude da tribunicia potestas ao concilia plebis a concessão do iustrium liberorum à Lívia, tendo encontrado oposição do comício (MOMMSEN, 1942, p. 442). Na interpretação dos

Quiritum. Lenel, assim como Mantovani, reconstituiu a fórmula dessa ação (SCHULZ, 1960, p. 45; LENEL, 1901, p. 236 et seq; MANTOVANI, 1999, p. 60-61 ep. 201-202).

${ }^{11}$ GAIO,1, 192: "[...] no se concede a la mujer ninguna acción derivada de la tutela, mientras que cuando los tutores realizan negocios de los pupilos o pupilas tienen que rendir cuentas después de la pubertad de éstos, merced a una acción de tutela”.Ver, também, ROTONDI, 1990, pp.275/276.

${ }^{12}$ Ademais, PAULO, D.23.2.44. Comentarios a la ley Julia y Papia, libro I - Dispone en la ley Julia de este modo: " $<$ Ninguno que es Senador, o el que es o fuere su hijo, o nieto habido de un hijo, o bisnieto habido de un hijo nacido de cualquiera de ellos, tenga a sabiendas con dolo malo por esposa o mujer una libertina, o a la que ella misma, o su padre o madre, representa, o hubiere representado, en las diversiones publicas; ni la hija de um Senador, o la nieta nacida de un hijo, o la bisnieta ha de un nieto nacido de um hijo se considere desposada o casada a sabiendas y con dolo malo con un libertino, o con el que el mismo, o su padre o madre, representa, o hubiere representado en las diversiones publicas; y ninguno de estos la tenga con dolo malo y a sabiendas por esposa o por mujer>". 
juristas, tal lei foi vinculada à Lex Iulia Pappia et Poppaee à Lex Iulia de adulteriis coercendis, ambas de 18 a.C.

Dentre as finalidades das leis, ressalta a de encorajar o matrimônio e a procriação, instituindo o ius liberorum às mulheres que tivessem levado a termo três gestações, (quatro, se fossem libertas). Livres da tutela legal, elas próprias geriam seu patrimônio, excetuado o dote, confiado à administração do cônjuge (CÍCERO, 1992, p. 217). ${ }^{13}$ Para além disso, as leis diminuíam os impedimentos derivados da patria postestas e do patronato, invalidavam os juramentos de celibato e viuvez e obrigavam ao casamento todos os homens e mulheres cidadãos, entre 25 e 60 e entre 20 e 50 anos, respectivamente. Diminuiu-se a idade legal para o ingresso na magistratura, que passou a depender do número de filhos, e limitou-se o ingresso de celibatários em festas e espetáculos públicos. Os filhos de libertos foram isentados de opera, desde que tivessem mais de um filho (não gladiador, nem comediante) e a quota viril do patrono foi retirada em relação ao patrimônio de liberto rico e com filhos (GAIO, 3, 42).14 Aumentou-se a capacidade sucessória de 1/10 sobre outro parente sucessível em razão de filho supérstite do matrimônio ou filho nascido e morto após 9 (nove) dias. O que o Príncipe almejava era manter pura a raça e regular as condições dos filhos de matrimônios mistos. A atividade da Jurisprudência se exercitou largamente sobre estas leis limitativas.

Dispondo sobre o adultério e o estupro, a Lex Iulia de adulteriis coercendis constituiu uma das inovações mais enérgicas e duráveis que registra a história do Direito Penal romano, uma vez que os atentados à castidade das mulheres eram disciplinados, até ao advento da lei, pelos tribunais domésticos, na própria família, e não pelo Estado, em juízos públicos e passíveis de pena criminal (MOMMSEN, 1907, p. 416 et seq). Os juízos públicos eram assim chamados porque sua execução era conferida a qualquer indivíduo do povo (Institutas 4.18.1). ${ }^{15}$ Pela dita lei, castigavam-se não somente os violadores das núpcias alheias, mas também os estupradores, ainda que o fizessem sem violência, a uma virgem ou viúva honesta. $\mathrm{O}$ processo apresentava numerosas e importantes particularidades de procedimento iniciando por uma quxstio especial sob a presidência do pretor; nas províncias, o processo iniciava ante ao governador (CÓDIGO, IX.9.32).16

Por matrimônio, não se compreendiam somente as iustas nuptias, senão todas as relações monogâmicas, e

\footnotetext{
${ }^{13}$ Verbis: "Y nada hay tan apropiado al derecho y a las disposiciones naturales (cuando digo derecho de la naturaleza quiero que se entienda $<$ ley>), como el poder de mando, sin em cual no pude mantenerse en pie casa alguna, ni ciudad, ni pueblo, ni el género humano entero, ni la naturaleza, ni el mundo. (....) y la vida de los hombres se atiene a las prescripciones de la ley suprema."

${ }^{14}$ GAIO, 3, 42: "Posteriormente, la ley Papia Popea aumentó los derechos de los patronos respecto a las herencias de libertos ricos. En efecto, dispone aquella ley que, cuando el liberto deja un património de cien mil o más sestércios, y menos de tres hijos, haya muerto com testamento o sin él, el patrono tenga derecho a una parte igual; así, pues, cuando el liberto deja un hijo o una hija como herederos, el patrono tiene derecho a la mitad, como si el liberto hubiese muerto sin hijos; cuando deja dos herederos o herederas tiene derecho a una tercera parte; si deja tres, el patrono queda excluido."

${ }^{15}$ INSTITUTAS, 4.18.1: "[...] 1.- Mas se llaman públicos, porque la ejecución de ellos se da la más de la veces á cualquier individuo del pueblo".
} 
a lei era relativamente igualitária, porque o cúmplice do adultério poderia ser penalizado. ${ }^{17}$ Nos termos da lei, só o pater podia matar a uma filha em adultério, se o ato fosse cometido na casa paterna. ${ }^{18} \mathrm{O}$ marido podia matar a mulher em flagrante adultério; se não a matasse, ficava obrigado ao divórcio, sob pena de lenocinium. Só poderia matar ao cúmplice em determinados casos. Quanto à ação, o prazo era de prescrição extintiva: 30 (trinta) dias para o marido, 60 (sessenta) ao pai, subsidiariamente e, depois de 4 (quatro) meses úteis, para qualquer cidadão (actio utile, ação popular). As penas iam desde a deserdação à incapacidade de ser testemunha em juízo ou testamento. No caso de adultério do marido, este era obrigado a restituir o dote. ${ }^{19}$ Matrimônio com adúlteras constituía lenocinium, nos termos do que está expresso no Corpus Iuris Civilis: "[...] a condenada pela lei Júlia sobre o pudor continue sujeita sempre às penas legais. Mas aquele que, sabendo disso, tomou ou voltou a tomar por mulher a condenada por adultério, que de qualquer modo tivesse se subtraído à pena capital, será castigado pela mesma lei por causa de lenocínio" (CÓDIGO, IX.9.9).

\section{CONSIDERAÇÕES FINAIS}

No que diz respeito à evolução constitucional romana, não foi descrita integralmente pelos próprios romanos e não se deixa facilmente descrever a posteriori: é preciso expor e ordenar todas as referências à ordenação das magistraturas e do poder político que aparecem esparsos nas fontes primárias que chegaram até nós (a ponta ínfima de um iceberg gigante) e, fundamentalmente, abordar o direito civil, que visa as relações entre cidadãos chefes de família, seguindo o método aristotélico (o direito só pode existir em uma cidade organizada diakaion politikon -). Gaio é o jurista antigo que oferece uma descrição global, de cunho jurídico-sociológico, da cidade romana tal como era, ou do ponto de vista das relações jurídicas em seu interior (os atores, os homens e seus papéis - pessoas; as coisas e seu estatuto - diversas espécies de coisas e, os negócios - ações).

No início da Era Cristã, a constituição republicana romana ganhou nova direção, tendo o regime, por obra

\footnotetext{
${ }^{16} \mathrm{Na}$ investigação de adultério, era possível torturar todos os escravos da casa no tempo em que se cometeu o delito, independentemente de que fossem do homem ou da mulher. Ver: Código. IX.9.32.

${ }^{17}$ Também ULPIANO, D.48.5.13,\$5: [ ... ] porque parece que es muy injusto que el marido exija à la mujer honestidad, de que él el marido no dé muestras; lo cual pude condenar también al marido, sin que la cosa se haga común a ambos por la compensación de mútuo delito."

${ }^{18}$ PAULO, Sentencias, II, 26, 1: "No segundo capítulo da Lex Julia, referente ao adultério, um pai adotivo ou natural é autorizado a matar um adúltero preso no ato com sua filha em sua própria casa ou na de seu genro. 2. Se um filho sob controle paterno, que é o pai, surpreender sua filha no ato de adultério, enquanto se deduz dos termos da lei que ele não pode matá-la, ainda assim, a ele deve ser permitido fazê-lo" (SPRUIT, BONGENAAR, 1984, p. 120).

${ }^{19}$ PAPIANO, D. 22.5.14. " De los adulterios, libro único. - Ciertamente sé que se discutió, żpodría acaso ser presentado como testigo al hacerse un testamento el condenado por adulterio? $\mathrm{Y}$ a la verdad, con justicia se le prohibirá el oficio de testigo. Estimo pues, que ni por derecho civl es válido el testamento, à que asistió un testigo de tal naturaleza, ni por derecho Pretorio, que sigue al derecho civil, de suerte que ni podrá adirse la herencia, ni darse la posesión de bienes"; PAULO, D.22.5.18: "De los adulterios, libro
} 
de César e Augusto, se transformado em uma espécie de "monarquia militar". Augusto, sob o argumento de restaurar os valores republicanos, editou um conjunto de leis ordenadoras das relações familiares, utilizando a moralização dos costumes com intenção claramente propagandística, uma vez que isso the permitiu ganhar a adesão social para o projeto de instauração de uma nova ordem constitucional. Até sua filha e neta - as Júlias - ele exilou, para dar exemplo.

Educado pela filosofia grega e pelo Direito Romano, o princeps compreendeu a constituição, em última instância, como ordenação social. Daí que faz parte da constituição a estrutura familiar, a educação, a propriedade, além da organização do poder político. Radical e rigorosa, portanto, a nova ordem constitucional do Principado romano no que tange à ordenação da família, pois as mulheres tiveram o seu status reforçado, libertando-se da tutela agnatícia formal pela prole. O paterfamilias deixou de ser o senhor absoluto da domus, ainda que tenha mantido algumas das suas prerrogativas tradicionais, como a vitaliciedade (é o chefe da família agnatícia enquanto for vivo ou enquanto não sofrer alteração de status) e a titularidade (é sempre pater familias, a não ser que transmita o seu poder sponte sua, libertando o seu alieni iuris pela emancipação).

Conquanto na Antiguidade não existisse a necessidade de uma definição rigorosa da parte que cabe a cada um - to dikaion ou ius - dentro da família, a Jurisprudência romana, não se ocupou das relações intrafamiliares. Preocupou-se com as relações entre os chefes de família. A econômica (arte de governar a família) se diferenciava do direito. Entre estas duas artes certamente existiam interferências e a justiça particular se exercia no interior da família com distribuições sem rigor e sem regra fixa, de modo que só se pode falar em "direitos imperfeitos" no que diz respeito às relações entre esposos, pais e filhos, senhores e servos. Foram as leis de Augusto que modificaram, parcialmente, essa realidade

O entendimento de que a estrutura familiar faz parte da constituição voltou a ter relevância no século XX, na medida em que, a partir dos anos 70, os países do norte da Europa (Alemanha, Holanda, Dinamarca, Suécia, etc...) iniciaram uma série de políticas públicas para diminuir o déficit previdenciário, sob a compreensão de que é a natalidade o centro da vida política, e não a mortalidade. O debate público atual, em particular no Brasil, volta a discutir a questão da natalidade, da mortalidade, da velhice e do custeio da Previdência e Assistência Social, estando em curso projeto de emenda constitucional para alterar o Regime da Previdência Social.

De outra parte, as constituições de feição democrático-social passaram a disciplinar, em grande medida, a ordenação da família, a ordem econômico e social e assim por diante. Na perspectiva doutrinária, discute-se o que é ou não matéria constitucional, a "constitucionalização do direito privado", ou a "constitucionalização do direito de familia" ou do "direito de propriedade. Por conseguinte, do ponto de vista material, a constituição não só

II - Por lo cuanto a ley Julia sobre los adulterios prohibe que la mujer condenada preste testimonio, coligiese que las mujeres tienen 
ordena os poderes públicos, mas desenha as bases da convivência social, de modo que se a constituição, modernamente, é entendida como o "estatuto jurídico da política", dela faz parte, necessariamente, a regulação da família e da atividade econômica. Isso é assim por que a constituição passa a ser entendida em termos institucionalistas: o Estado e a Administração são empreendimentos que se realizam e que duram juridicamente no meio social. Para a realização desta ideia, um poder se organiza, e, de outra parte, entre os membros do grupo social interessados na realização da ideia, se produzem manifestações de comunhão dirigidas aos órgãos do poder e às regras de procedimento.

A constituição é, pois, um processo real e concreto de colaboração e o direito, uma ordem (conjunto de relações de justiça) que decorrem da finalidade (telos) de uma comunidade concreta. Daí ser a constituição em sentido absoluto a estrutura concreta da unidade política e da ordenação social em um Estado determinado. Se Augusto tinha consciência disso quando promoveu a reforma da constituição romana ou se apenas intuiu a realidade institucional da constituição, é coisa que não temos como saber. Todavia, sabemos, com segurança, que ele foi o primeiro governante de Roma a promover, conscientemente, a intervenção radical da civitas na família e a usar reforma dos costumes como elemento de propaganda para consolidar o regime político. Por que foi um acontecimento memorável, é preciso que a tradição jurídica selecione, nomeie, transmita e preserve, indique tesouros esquecidos e o seu valor, de modo a criar uma continuidade consciente no tempo que nos desliga, ainda que temporariamente, do ciclo biológico das criaturas que vivem no mundo.

\title{
POLITICAL ADVERTISING ON ROMAN PRINCIPATE: THE FAMILY AS AN ELEMENT OF THE CONSTITUTION
}

\begin{abstract}
This paper analyses the transformation's moment of roman constitution, in wich the civitas interfered in the family, serving the reform of the customs of element of propaganda. The first hypothesis is that in Rome, until the time of the instauration of the military monarchy, public law did not concern family relations. With the constitution of the principate, a normative set emerged which, directly interfering in the organization of the family and in the freedom of individual choice, ended up bringing to the field of politics the solution of intrafamilial conflicts, with the creation of public judicial procedures, not submitted to logic of the form process (semi-private), mainly to discipline sexual relations (the public judgments of adulteries) and, therefore, to equate the birth issue. The method used in the investigation is historical-legal, because the historicity of law is constitutive and an integral part of the events. In the style of historical realism, the study seeks to understand and explain the foundations of political practice and the propaganda, which were the basis of the new regime, with the aid of the scientific results of historical-legal research on the subject (bibliographic review) and primary documentary sources (texts of jurists, politicians and historians of Classical Antiquity).
\end{abstract}

derecho de prestar testimonio en juicio." 
Keywords: Constitution; Social Ordination; Family; Political Advertising; Leges Julix.

\section{REFERÊNCIAS BIBLIOGRÁFICAS}

ABBAGNANO, Nicola. Dicionário de Filosofia. São Paulo: Editora Mestre Jou, 1970.

ARANGIO-RUIZ, Vicente. Historia del Derecho Romano. 5. ed. Madrid: Reus, 1994.

ARENDT, Hannah. La condición humana. Barcelona: Paidós, 1993.

Poder e violência. Rio de Janeiro: Relume Dumará, 2001.

ARISTÓTELES. Política. Lisboa: Vega, 1998.

AUGUSTO. Res Gestae. Disponível em: <http://www.thelatinlibrary.com>. Acesso em: 27 fev. 2017.

BONFANTE, Pietro. Instituciones de derecho romano. Madrid: Centro de Enseñanza y Publicaciones, s.d.

BURDESE, Alberto. Manuale di diritto pubblico romano. Terza Edizione.Torino: UTET, 1987.

CÍCERO, Marco Túlio. Sobre la República. Sobre las Leyes. 2. ed. Madrid: Editorial Tecnos, 1992.

COLLIVA, Paolo. In: BOBBIO et al. (Orgs.). Dicionário de política. Brasília: UnB, 1996.

DOMINGO, Rafael et al. (Coord.). Textos de Derecho Romano. Navarra: Editorial Aranzadi, 2002.

EPICURO/LUCRÉCIO/CÍCERO/SÊNECA E MARCO AURÉLIO. Coleção “Os Pensadores”. São Paulo: Abril Cultural, 1980.

ERNOUT, A.; MEILLET, A. Dictionnaire Étymologique de la Langue Latine: Histoire des Mots. 4. ed. Paris: Klincksieck, 1985.

FREUND, Julien. La essence du politique. Paris: Sirey, 1965.

GARCÍA DEL CORRAL, D. Ildenfonso. Cuerpo del derecho civil romano. Valladolid: Lex Nova, 1989.

LENEL, Otto. Essai de reconstitution de l'édit perpétuel. Trad. de Frédéric Peltier, revisada por el autor. Paris: Librairie de La Société du Recueil Général des Lois et des Arrêts, 1901.

MANTOVANI, Dario. Le formule del processo privato romano: per la didattica delle istituzioni di diritto romano. Padova: CEDAM, 1999.

MOMMSEN, Theodor. Compendio del Derecho Publico Romano. Buenos Aires: Editorial Impulso, 1942. 
MOMMSEN, Theodor. Droit penal romain. T II. Paris: Albert Fontemoing, Éditeur, 1907.

MOMMSEN, Theodor. Historia de Roma. Livro V. Madrid: Turner, 1983.

POLÍBIOS. História. Brasília: Editora UnB, 1996.

ROTONDI, Giovanni. Leges publicae populi romani. In: ENCICLOPEDIA Giuridica Italiana. Hildesheim, Zurich, New York: Olms, 1990.

SCHULZ, Fritz. Derecho romano clássico. Barcelona: Bosch, 1960.

Principios del Derecho Romano. Madrid: Civitas, 1990.

SPRUIT, J.E.; BONGENAAR Gaius en Paulus. Zutphen: De Walburg Pers, 1984.

SUETONIO. A Vida dos Doze Cesares. São Paulo: Ediouro, s/d. O Divino Augusto. Lisboa: Livros Horizonte, 1975.

TABORDA, Wilmar. Poder político e Direito de Família: o sujeito de direito no âmbito da família. Uma visão histórico-política. Porto Alegre: Editora AGE Ltda, 2010.

TÁCITO, C. Cornelio. Anais. Livro I, 2. São Paulo: Ediouro, s/d.

THOMAS, Yan. A divisão dos sexos no direito romano. História das mulheres - Antiguidade. Porto/São Paulo: Afrontamento, Ebradil, 1993.

VEYNE, Paul. História da vida privada. Antiguidade ao ano mil. São Paulo: Companhia das Letras, 1996.

VOCI, Pasquale. Esame delle tesi del Bonfante sulla famiglia romana arcaica. In: LAURIA, Mario (Org.). Studi in Onore di Vicenzo Arangio-Ruiz. Napoli: Edittore Jovene, 1956. v. 1. p. 101-146.

WHITE, Hayden. Metahistoria. La imaginación histórica en la Europa del siglo XIX. México: Fondo de Cultura Económica, 1992.

Trabalho enviado em 11 de novembro de 2017.

Aceito em 19 de janeiro de 2018. 